\title{
Goal choices and planning: Distinct expectancy and value effects in two goal processes
}

Citation for published version (APA):

Sun, S., Vancouver, J. B., \& Weinhardt, J. M. (2014). Goal choices and planning: Distinct expectancy and value effects in two goal processes. Organizational Behavior and Human Decision Processes, 125(2), 220-233. https://doi.org/10.1016/j.obhdp.2014.09.002

Document status and date:

Published: $01 / 11 / 2014$

DOI:

10.1016/j.obhdp.2014.09.002

Document Version:

Publisher's PDF, also known as Version of record

Document license:

Taverne

\section{Please check the document version of this publication:}

- A submitted manuscript is the version of the article upon submission and before peer-review. There can be important differences between the submitted version and the official published version of record.

People interested in the research are advised to contact the author for the final version of the publication, or visit the DOI to the publisher's website.

- The final author version and the galley proof are versions of the publication after peer review.

- The final published version features the final layout of the paper including the volume, issue and page numbers.

Link to publication

\footnotetext{
General rights rights.

- You may freely distribute the URL identifying the publication in the public portal. please follow below link for the End User Agreement:

www.umlib.nl/taverne-license

Take down policy

If you believe that this document breaches copyright please contact us at:

repository@maastrichtuniversity.nl

providing details and we will investigate your claim.
}

Copyright and moral rights for the publications made accessible in the public portal are retained by the authors and/or other copyright owners and it is a condition of accessing publications that users recognise and abide by the legal requirements associated with these

- Users may download and print one copy of any publication from the public portal for the purpose of private study or research.

- You may not further distribute the material or use it for any profit-making activity or commercial gain

If the publication is distributed under the terms of Article $25 \mathrm{fa}$ of the Dutch Copyright Act, indicated by the "Taverne" license above, 


\title{
Goal choices and planning: Distinct expectancy and value effects in two goal processes
}

\author{
Shuhua Sun ${ }^{\mathrm{a}, *}$, Jeffrey B. Vancouver ${ }^{\mathrm{b}}$, Justin M. Weinhardt ${ }^{\mathrm{c}}$ \\ a School of Business and Economics, Maastricht University, Room A2.06, Tongersestraat 53, 6211 LM Maastricht, The Netherlands \\ ${ }^{\mathrm{b}}$ Department of Psychology, Ohio University, Porter Hall 221, Athens, $\mathrm{OH}$ 45701-2979, United States \\ ${ }^{\mathrm{C}}$ Haskayne School of Business, University of Calgary, Scurfield Hall 442, Calgary, AB T2N 1N4, Canada
}

\section{A R T I C L E I N F O}

\section{Article history:}

Received 3 January 2014

Accepted 5 September 2014

Available online 1 October 2014

Accepted by Steven Farmer

\section{Keywords:}

Motivation

Goal choice

Goal planning

Expectancy

Value

\begin{abstract}
A B S T R A C T
Expectancy and value have emerged as two major determinants of motivation. However, the exact nature of their functioning is less clear given that previous research failed to test adequately different goal processes. Based on the recent nonmonotonic, discontinuous model of expectancy elaborated by Vancouver, More, and Yoder (2008), two studies were conducted and found that expectancy and value functions in different forms during the goal choice versus goal planning processes. Specifically, the two constructs positively and jointly predicted one's goal choice, whereas they played independent and opposite roles in affecting the allocation of effort during the goal-planning process. These findings address gaps in theories of motivation, allow for more precise specifications of the roles for expectancy and value within such models, and further efforts toward integrating theories of motivation within a goal-centered, selfregulation framework.
\end{abstract}

(c) 2014 Elsevier Inc. All rights reserved.

\section{Introduction}

Motivating oneself or one's employees to perform well is a constant struggle (Pinder, 2008). Applied psychologists have attempted to help with this struggle by providing theories of, and research on, human motivation (Diefendorff \& Chandler, 2011; Kanfer, 1990; Mitchell \& Daniels, 2003a,2003b). Two concepts that emerged early in cognitive theories of motivation and still pervade modern research programs (cf. Hyland, 1988; Miner, 2005) are (a) the expectancies one has regarding the possible outcomes that might come to pass given choices, behaviors, or performances and (b) the value one associates with those possible outcomes (Kanfer, 1990). Theories that use these constructs tend to be called $E * V$ theories because they described expectancies $(E)$ as interacting with anticipated value $(V)$, also called valence, to predict choice and effort. For example, Vroom (1964) refers to the product of expectancy and valence for an option as the motivational force for that option, and decision making theories (e.g., Edwards, 1954) refer to it as the expected utility for an option. These theories predict that the probability of an option being chosen is likely to

\footnotetext{
* Corresponding author. Address: Department of Organization and Strategy, School of Business and Economics, Maastricht University, Room A2.06, Tongersestraat 53, 6211 LM Maastricht, The Netherlands. Fax: +31 433884893.

E-mail addresses: s.sun@maastrichtuniversity.nl (S. Sun), vancouve@ohio.edu (J.B. Vancouver), justin.weinhardt@haskayne.ucalgary.ca (J.M. Weinhardt).
}

increase as valued incentives (e.g., money; respect) are increased for outcomes linked to that option (Van Eerde \& Thierry, 1996). The interaction (i.e., the multiplicative function) notion reflects the idea that an option with no outcome of value (i.e., zero valence) or of no believed probability of being obtained (i.e., zero expectancy) has no motivational force and that the motivating force of some specific value increases as the expectation of obtaining an outcome of that value increases (Vroom, 1964).

For a while, $E * V$ theories were the de rigueur of motivation theories in applied psychology (Campbell \& Pritchard, 1983; Kanfer, 1990). However, lack of consistent empirical support for the multiplicative function (Ambrose \& Kulik, 1999; Van Eerde \& Thierry, 1996) and the rise of the goal construct within the field (Austin \& Vancouver, 1996) relegated expectancy and value concepts to supporting roles (Diefendorff \& Chandler, 2011; Klein, Austin, \& Cooper, 2008; Locke \& Latham, 1990). Current motivational theory defines goals as internally represented desired states whose properties, like difficulty, specificity, and importance, largely determine motivation (Austin \& Vancouver, 1996; Diefendorff \& Chandler, 2011). These goals come about and operate via several goal processes, including goal-choice, goal-planning, goal-striving, and goal-revision (Austin \& Vancouver, 1996). For example, goal-choice processes determine what goals individuals strive to achieve and at what level (Klein et al., 2008), and goal-planning processes can, among other things, determine the amount of resources mustered ahead of time to achieve a goal (Vancouver, More, \& Yoder, 2008). 
Goal choice and planning processes are considered highly cognitive and thought to use expectancy and value beliefs (Bandura, 1986; Klein et al., 2008).

However, the nature of the relationships expectancy and value have across the goal processes remains an issue for those seeking a comprehensive goal-based model of motivation (Locke \& Latham, 2004). In particular, it is not clear whether expectancy and value play roles in all the goal processes, much less, whether the roles are identical. Decades ago some theorists assumed that expectancies and value had similar roles across processes (e.g., Atkinson, 1957; Vroom, 1964), whereas others assumed their roles likely differed (e.g., Terborg \& Miller, 1978). Unfortunately, contemporary theories continue to be either non-committal or contradictory with regards to the roles of expectancy and value across the goal processes (e.g., Bandura, 1997; Carver \& Scheier, 1998). The purpose of the study is to address this critical gap in order to facilitate further integration of expectancy and value into goal-directed, selfregulation models of motivation given their conceptual importance in these theories (Carver \& Scheier, 1982; Hyland, 1988; Kanfer, 1987; Klein, 1989; Locke \& Latham, 2004; Seo, Barrett, \& Bartunek, 2004; Vancouver, 2008).

One primary reason for the uncertainty regarding the functional roles of expectancy and value is the lack of quality research on $E * V$ theories (Pinder, 2008). First, most research used betweensubject designs (Schwab, Olian-Gottlieb, \& Heneman, 1979; Van Eerde \& Thierry, 1996), despite the fact that most $E * V$ theories focus on describing choices among options an individual faces. That is, $E * V$ theories describe choice as a function of relative motivational force of the different options an individual faces (Mitchell, 1974), yet most research examined the expectancies and values different individuals had for a particular option.

Second, many studies in applied psychology use passive observational designs with questionable measurement properties (Anderson, 1970) rather than experiments, reducing the ability to draw causal conclusions (Hanges \& Wang, 2012). For example, when Van Eerde and Thierry (1996) meta-analytically summarized the $E * V$ literature to examine the validity of expectancy theories, they acknowledged that the primary studies that they used were observational in nature, such that "the direction of the effects cannot be established" (p. 582) and concluded that "the results of the current meta-analysis do not increase our understanding of motivated behavior" (p.582). They called for studies using within-subject experimental designs to address the validity of expectancy and value in explaining motivation.

Finally, the empirical protocols used in existing studies often conflated goal processes, obscuring the distinct roles expectancy and value might play across goal processes (Terborg, 1976) or confounding other constructs (e.g., ability). For instance, ability and expectancy are confounded in measures of effort applied during goal striving, and measures of performance likely include the results of multiple goal processes (Kanfer, 1987). Moreover, performance is also affected by third variables such as ability (Phillips \& Gully, 1997). Instead, a measure of willingness to expend resources in a planning context should more directly assess the motivating role of expectancy and value (Kanfer, 1987; Vancouver et al., 2008).

Fortunately, a recently developed protocol addresses these issues. Specifically, Vancouver et al. (2008) used a repeated-measures design to obtain within-person models of the effect of manipulated levels of expectancy on two motivational measures: choice of whether to pursue a goal and, if chosen, the planned magnitude of effort one is willing to commit to the goal. The use of repeated-measures allowed the researchers to develop within-person models; the use of a manipulation allowed causal inferences; and the use of two measures of motivation applied before the person begins to strive for the goal separated goal-choice (direction of effort) from goal-planning (degree of effort). They found that expectancies positively affected goal choice, but negatively affected the degree of effort set aside to seek the goal, providing evidence that expectancy plays distinct roles across goal processes.

Yet, the Vancouver et al. (2008) study only looked at the expectancy construct. They did not include a manipulation of value. Thus, the issue of the functional form of the relationships between expectancy and value for the goal-choice and goal-planning processes remains unresolved, i.e., whether either or both concepts are involved in both processes, and what forms their joint effects take (i.e., are they multiplicative or additive). In the current paper, we present two studies that examine the functional roles of value, in addition to the role of expectancy, on direction and degree of effort using the Vancouver et al. (2008) protocol. In so doing, we address many of the above-mentioned design issues of existing studies that constitute the basis of Van Eerde and Thierry's (1996) meta-analysis and extend Vancouver et al.'s (2008) study by addressing the role of value and more importantly presenting empirical information regarding whether and how value might interact with expectancy in affecting the direction and degree of effort. We begin with a review of the role of expectancy and value within goal theories, and the more recent work by Vancouver et al. (2008) on the role of expectancy across goal processes.

\section{A review of the role of expectancy and value in goal theories}

Several scholars have proffered alternative goal-based theories of work motivation (e.g., Cropanzano, James, \& Citera, 1993; DeShon \& Gillespie, 2005; Klein, 1989; Locke \& Latham, 2004; Lord \& Levy, 1994; Vancouver, 2008), often based on larger comprehensive theories of human behavior (e.g., Bandura, 1986; Carver \& Scheier, 1998; Powers, 1973). These comprehensive goal-based theories conceptualize behavior as a function of discrepancies between what one desires (i.e., goals) and where one is (Hyland, 1988; Lord, Diefendorff, Schmidt, \& Hall, 2010; Vancouver, 2008). Moreover, they tend to agree regarding the way goals are adopted via a goal-choice process. Specifically, they incorporate $E * V$ notions to predict that expectancies positively affect goal adoption and the level of self-set goals (e.g., Klein et al., 2008; Locke \& Latham, 1990). Likewise, these theories predict that incentives or other sources affecting anticipated value (e.g., valence) will increase the likelihood individuals will adopt or select a goal (e.g., Riedel, Nebeker, \& Cooper, 1988). Moreover, most of these theories describe a multiplicative function (i.e., $E * V$ ). However, Nagengast et al. (2011) noted that in the last decade or so, some researchers have tended to drop the multiplicative notion for an additive one or are ambiguous on this point, whereas others are explicit about retaining it (e.g., Steel \& Konig, 2006; Vancouver, Weinhardt, \& Schmidt, 2010).

Goal-based theorists also agree that processes beyond goal choice, like goal planning, goal striving, and goal revising are relevant to understanding human behavior (Diefendorff \& Lord, 2008). However, one of these processes, goal planning, has received relatively little theoretical or research attention (Gollwitzer, 1990). Yet, goal planning, like goal choice, likely involves beliefs about future conditions, making expectancy and value beliefs potentially relevant (Bandura, 1986). Another advantage to examine goal planning is that resources allocated to one's goal reflects the extent an individual is willing to invest their finite valuable resources; thus, resources allocated represents a more direct measure of motivation as compared with performance, which confounds ability, task difficulty, and other constructs (Kanfer, 1987; Seo \& Ilies, 2009; Vancouver \& Kendall, 2006).

Yet, on the question of goal-planning processes, many comprehensive goal-based theories are moot. Where planning processes are explicitly considered, the theories appear contradictory. For example, within social cognitive theory Bandura (1986) argued 
that self-efficacy, a type of expectancy belief (Bandura, 1977), might negatively relate to efforts in a preparatory or planning stage, but more recently argued the opposite (e.g., Bandura, 2012). On the other hand, control theorists (e.g., Carver \& Scheier, 1998; Vancouver et al., 2008) clearly suggested that expectancies like self-efficacy negatively relate to resources mustered prior to goal striving given the likely lower need for resources during goal striving for more capable individuals or under more favorable conditions.

To address the specific question of the role of expectancy in the goal-choice versus goal-planning processes, Vancouver et al. (2008) noted that extant research often used non-diagnostic or inappropriate research designs (see also Pinder, 2008; Van Eerde \& Thierry, 1996). To address the design limitations, Vancouver et al. manipulated several levels of expectancy via the difficulty of the task using a repeated-measures design. That is, participants were presented with a series of tasks (i.e., targets) that predictably varied in terms of likelihood of achieving the goal. Upon each presentation, participants were asked whether they wanted to attempt the task or not, which was used as a measure of direction of effort and presumably indicated the result of a goal-choice process. If they wanted to attempt the particular instance (i.e., they had accepted the goal), they were asked to determine the amount of time they wanted to put to that particular instance, which was used as a measure of degree of effort and presumably indicated the result of a goal-planning process. Vancouver et al. found that expectancy positively related to goal acceptance (i.e., direction of effort), but negatively related to the amount of time allocated to accepted goals (i.e., degree of effort).

The Vancouver et al. (2008) finding can be represented using a single line graph (Fig. 1). The graph represents a discontinuous, nonmonotonic relationship between expectancy beliefs and resources (i.e., time) allocated. The discontinuity is represented by the vertical line and the nonmonotonicity is represented by the jump up at the point of the discontinuity and the slope down from the point of the discontinuity onward as one moves from left to right. This function presumably results from a three-step process (Carver \& Scheier, 1998; Vancouver et al., 2008). First, expectancies are used to estimate the amount of resource (e.g., time) needed to achieve the goal. The lower the expectancies, the higher the estimated resource need. Second, this estimate is compared to a threshold. If exceeded, no resources are allocated because the goal is not accepted. This is the goal-choice step. The third, planning step, occurs only if the goal is chosen and the context demands a plan. Specifically, within a planning process, the individual uses the estimate of resource need to determine how much to allocate when allocation decisions need to be made ahead of time. When expectancies are relatively low, this process allocates more resources compared to when expectancies are relatively high because of the estimate of need (Vancouver et al., 2008).

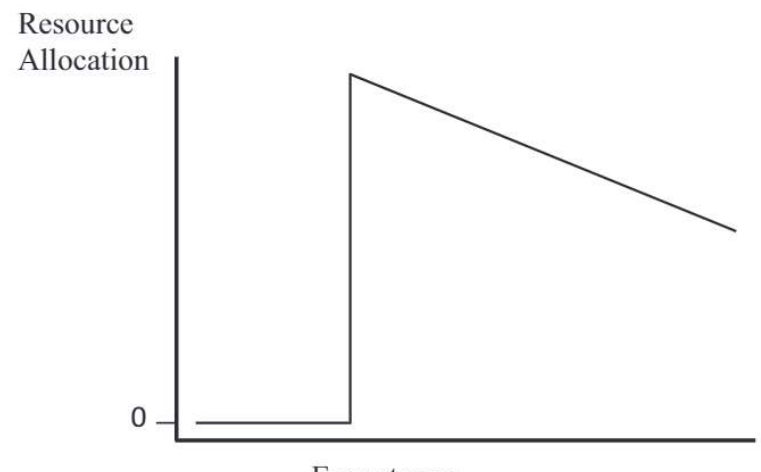

Expectancy

Fig. 1. The nonmonotonic, discontinuous model of expectancy.
Although Vancouver et al. (2008) elaborated the role of expectancy across goal choice and planning processes, they did not address the roles of value in these processes. Indeed, goal theories are also moot or mixed in terms of the role of value. For example, Locke and Latham's (2004) integrated model of work motivation, which is largely based on social cognitive theory, states that incentive effects will be mediated through goal choice only. That is, there will be no effect of value on degree of effort beyond the application of effort for a chosen goal. Likewise, Carver and Scheier (1998) describe no role for value or incentives in determining the degree of effort allocated in a plan. In contrast, other self-regulation theories seem to say that incentives might influence the degree of effort planned for goal pursuit (e.g., Hyland, 1988). Though perhaps the fairest thing to say about control theories is that they have very little to say about goal-planning processes in general (Diefendorff \& Lord, 2008).

One reason for the vagueness regarding planning processes is likely due to the state of the empirical literature. With the exception of research on the effectiveness of planning on goal attainment (e.g., Frese \& Zapf, 1994; Gollwitzer \& Oettingen, 2011; Kirschenbaum, 1985), little research attention has been paid to factors that affect the process. Indeed, social cognitive theory (Bandura, 1986) and the integrated model of work motivation (Locke \& Latham, 2004) presumably require empirical findings before including links between constructs (Locke, 2007). Moreover, the inversion of the effect of expectancy on effort allocation during goal choice versus goal planning observed by Vancouver et al. (2008) renders a simple extrapolation of expectancy and value's roles across these processes (cf., Atkinson, 1957) problematic. Therefore, in the sections that follow we first review possible functional forms of value with (or independent of) expectancy across the two goal processes given the discontinuous, nonmonotonic model found for expectancy. We then conduct two studies to empirically compare the functions across the two processes of choice and planning. By doing so, we address gaps among existing goal-based theories of motivation regarding the roles for expectancy and value within such models, and further efforts toward integrating theories of motivation within a goal-centered, self-regulation framework.

\section{Alternative models of the role of value}

First, there appears to be consensus that both values and expectancy influence goal-choice processes (Klein et al., 2008), though the specific processes, and possibly the joint form of their effects, differ. Typically, theorists describe a weighting (i.e., multiplicative) function that combines expectancies and values into an expected utility value that is compared to other expected utilities for determining choice (e.g., Baron, 2004). Alternatively, Wright and Brehm (1989), who also ascribe to the model represented in Fig. 1, argued that goal value affects the resource threshold used in the goal-choice process. For instance, when confronted with goals with relatively higher value, as might occur when an incentive is higher, the resource threshold level (i.e., the maximum resources allowed) will rise. This will move the point of discontinuity to the left, which decreases the expectancy needed for an acceptable goal and increases the probability goals will be accepted (see Fig. 2a). It also creates a steeper positive slope between expectancy and the probability of accepting the goal for higher valued goals. Yet, this process also predicts an interaction between expectancy and value on goal acceptance as shown in a simulation of this threshold effect (see Fig. 3).

Of interest, Vancouver et al. (2010) described a computational model of multiple-goal choice that integrated the classic theorizing of a multiplicative expectancy-value function from decision making (Baron, 2004) and motivational theories (Kanfer, 1990) with the goal-based control theory conceptualization (e.g., Carver \& Scheier, 


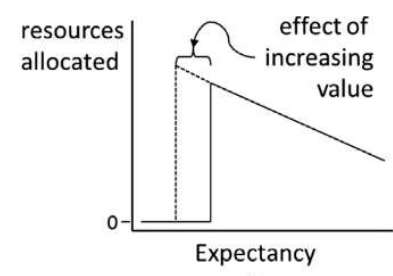

a

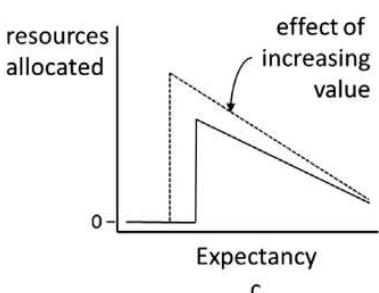

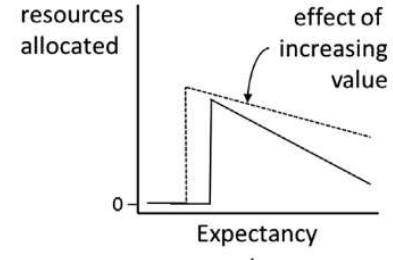

b

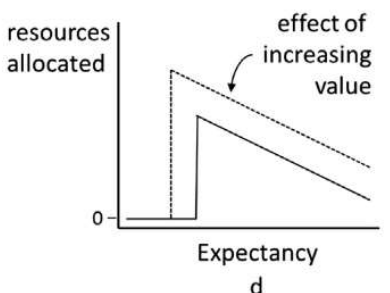

Fig. 2. Summary of empirical models.

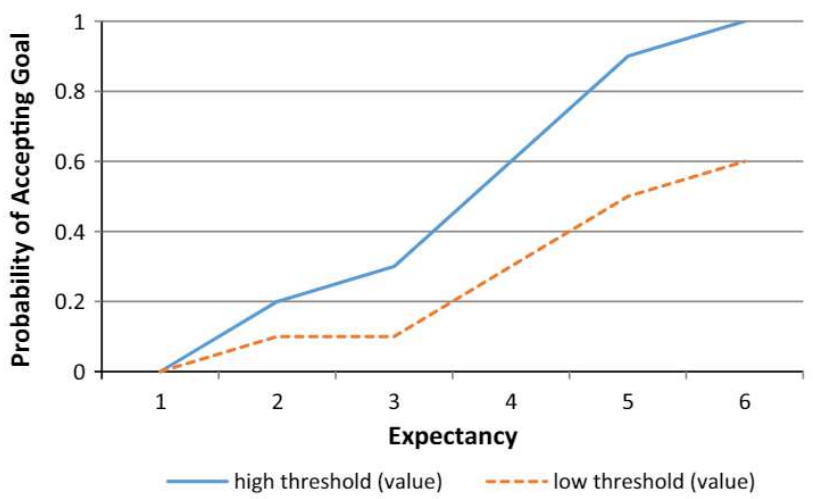

Fig. 3. Probability of accepting goal as function of expectancy and value.

1998; Hyland, 1988; Wright \& Brehm, 1989). In the Vancouver et al. (2010) model, the discrepancy between a goal and the current state, weighted by importance, is assumed to create a signal that represents the immediate, subjective value for the goal. In the Vancouver et al. (2008) paradigm, discrepancy is constant at the time of choosing a goal (i.e., the goal is to hit a target and the target is not hit prior to making a choice), meaning that subjective value would vary only if the importance weight varies. This importance weight, also called error sensitivity or gain in control theories (e.g., Hyland, 1988; Vancouver, 2008), might be somewhat a function of value manipulated via incentives or other mechanisms (Schmidt \& DeShon, 2007). Meanwhile, according to the model, subjective value is multiplied by the expectancy of reaching the goal to determine the expected utility of choosing to accept the goal. This expected utility is then compared to the expected utility of options, which in the case of the Vancouver et al. (2008) paradigm, would be hypothetical future options. In this way, the expected utility of future options is the threshold described in control theory models of goal processes (e.g., Carver \& Scheier, 1998). Only unlike the description in Wright and Brehm (1989), this theory suggests that value raises the expected utility of accepting the goal that is compared to the threshold (i.e., the expected utility of hypothetical future options) rather than raising a threshold of resources one would be willing to allocate. Nonetheless, the result would be the same in terms of the goal-choice process. That is, expectancy and value would interact to determine goal choice because of the weighting function.

That said, there is no requirement within control theories that the signal that is compared to the threshold be calculated using a
Table 1

Sign of effects for the different models.

\begin{tabular}{|c|c|c|c|c|c|c|}
\hline \multirow[t]{2}{*}{ Fig. 2 model } & \multicolumn{3}{|c|}{ Direction of effort } & \multicolumn{3}{|c|}{ Degree of effort } \\
\hline & Expectancy & Value & $E * V$ & Expectancy & Value & $E * V$ \\
\hline $\mathrm{a}$ & + & + & + & - & 0 & 0 \\
\hline b & + & + & + & - & + & + \\
\hline c & + & + & + & - & + & - \\
\hline d & + & + & + & - & + & 0 \\
\hline
\end{tabular}

Note. E: Expectancy; V: Value.

multiplicative function. It could be additive. Indeed, some reviewers of the motivation literature questioned the use of a multiplicative function for theories of choice (e.g., Ambrose \& Kulik, 1999) and others were vague on the point (as noted by Nagengast et al., 2011). However, given the poor quality of research on this question within the motivation domain, quality empirical work would help confirm the specific form of the function. Indeed, no theories explicitly suggesting an alternative to the interactional relationship of expectancy and value on goal choice. Moreover, decades of quality empirical work from decision-making researchers implicate a multiplicative function (Baron, 2004). Thus, we predicted that the functional form of expectancy and value on choice (i.e., direction of effort) would be positively multiplicative. To be more specific, we expect that expectancy, value, and the product term of the two will be positively related to the probability of choosing the goal (see Table 1), which is the quality of the function that would produce the effect illustrated in Fig. 3, though constrained to be smooth, straight lines.

However, for goal planning, much more ambiguity exists. For example, several theories describe no effect for value (or incentives) on the magnitude of resources allocated independent of the effect of goal levels (e.g., Wright \& Brehm, 1989), including several explicitly integrative theories of expectancy-value and goals (e.g., Klein, 1991; Locke, 2004). Yet, several other theories, as well as some research, suggest that value will impact both goal choice and goal planning (Hyland, 1988; Pritchard \& Curts, 1973; Terborg, 1976; Yancey, Humphrey, \& Neal, 1992). For example, motor control theory models of behavior note that the goal importance weight (i.e., gain or error sensitivity) determines the degree of the response to a goal discrepancy (Hyland, 1988; Jagacinski \& Flach, 2003).

However, if value is used along with expectancy in goal planning, the combinatory rule is less clear. For one thing, expectancy's influence is negative (Vancouver et al., 2008). Thus, if interactional with value, it is not clear what the sign of the interaction might be. For instance, an expected utility model (Baron, 2004; Schoemaker, 1982) would advocate different interactive effects between expectancy and value on effort planned for a single goal, depending on how one looked at the problem. That is, if one considers the expected value of a unit of effort, that expected value would be greater for high expectancy goals, meaning incentives might motivate the individual to raise effort more for high expectancy goals. This would result in a positive interaction between expectancy and values on effort committed similar to positive interaction with goal choice (see Fig. 2b).

Alternatively, Vancouver et al. (2008) argued that the negative expectancy effect reflects the idea that one needs to compensate for the difficulty of the task with effort. Specifically, need increases as expectancy decreases. Thus, if an incentive is motivating more effort, then incentives could motivate extra compensation on the low expectancy goals compared to the high expectancy goal. This would be similar to compensating for uncertainty where a low expectancy goal has greater uncertainty and therefore requires greater time. Moreover, it would involve weighting the output from a goal system not by expectancy, as in the goal choice process, but by anticipated need. The result would be a negative interaction 
between expectancy and value (Fig. 2c) because anticipated need is the inverse of expectancy.

Finally, an additive model might also hold, where value raises the resources allocated with equal weight to each of the expectancy levels (Fig. 2d). There is insufficient theory or evidence to predict which of these models will be supported. Given that a primary issue is that much of the existing research does not carefully distinguish between the goal processes or use strong, readily interpretable designs, we sought to address the knowledge gap with an empirical study that manipulated both expectancy and value. In particular, we added an incentive manipulation to Vancouver et al.'s (2008) paradigm used to study the effects of expectancy on goal selection and planning.

Table 1 presents the sign of the effects for the alternative models. As indicated, we hypothesized that for direction of effort, expectancy and value would positively interact with each other in addition to their positive main effects. As for degree of effort, we hypothesized a negative main effect for expectancy. Given the above discussion, we presented several alternative models for the main effect of value (positive versus null), and its interaction with expectancy (negative, positive versus null) for degree of effort. The specific sign of the effects for the alternative models are reflected in Models a through $\mathrm{d}$ in Table 1.

Finally, in contrast to the Vancouver et al. (2008) study, we also wanted to examine performance effects of expectancy, value, and the goal processes. Presumably, these goal processes subsequently affect performance, but for reasons articulated by Kanfer (1987) and Vancouver et al. (2008), performance is a poor proxy for motivation. Nonetheless, a close examination of performance can be informative on several levels. In particular, in terms of performance it appears that the participants in Vancouver et al. (2008) study were only somewhat judicious in terms of choosing a target and allocating resources based on the expectancy associated with the targets. That is, individuals were more likely to skip difficult targets and nearly always attempted the easier targets. They also reserved more resources on the relatively easier targets that were attempted. However, if performance was understood in terms of the number of target hits, the Vancouver et al. (2008) participants were not nearly as judicious as they could have been. For example, the participants allocated resources to $69 \%$ of the most difficult targets even though at the maximum level of resource use (i.e., $10 \mathrm{~s}$ ) they only were likely to achieve the goal about $5 \%$ of the time. To be sure, there was a penalty of $3 \mathrm{~s}$ for skipping a target, and no monetary relevance for success or failure; yet, it appears that individuals were not using their past performance information very well. To examine this more closely, we removed the 3-s penalty for skipping a target found in the Vancouver et al. (2008) protocol and had monetary incentives tied to performance.

\section{Study 1}

\section{Method}

\section{Participants}

Participants in this study were 36 undergraduate students who received course credit for their psychology class. These 36 participants provided 4051 sets of observations due to the repeated-measures nature of the study design. Sixty-one percent of the participants were female. Their average age was 19 years old $(S D=1.31)$.

\section{The task}

The task used in the present study was the hurricane game protocol (Vancouver et al., 2008), which is a computer game that requires repeated resource allocation decisions under varying conditions. The object of the game is to click on "boards" (i.e., square targets) moving randomly within the specified space on a computer screen (see Fig. 4). A central feature of the game is that the targets varied in size (see the six target sizes in Fig. 4), which affects the difficulty of nailing them (i.e., smaller targets are harder to click on than larger targets) as well as the perceived probably of nailing them (i.e., expectancy).

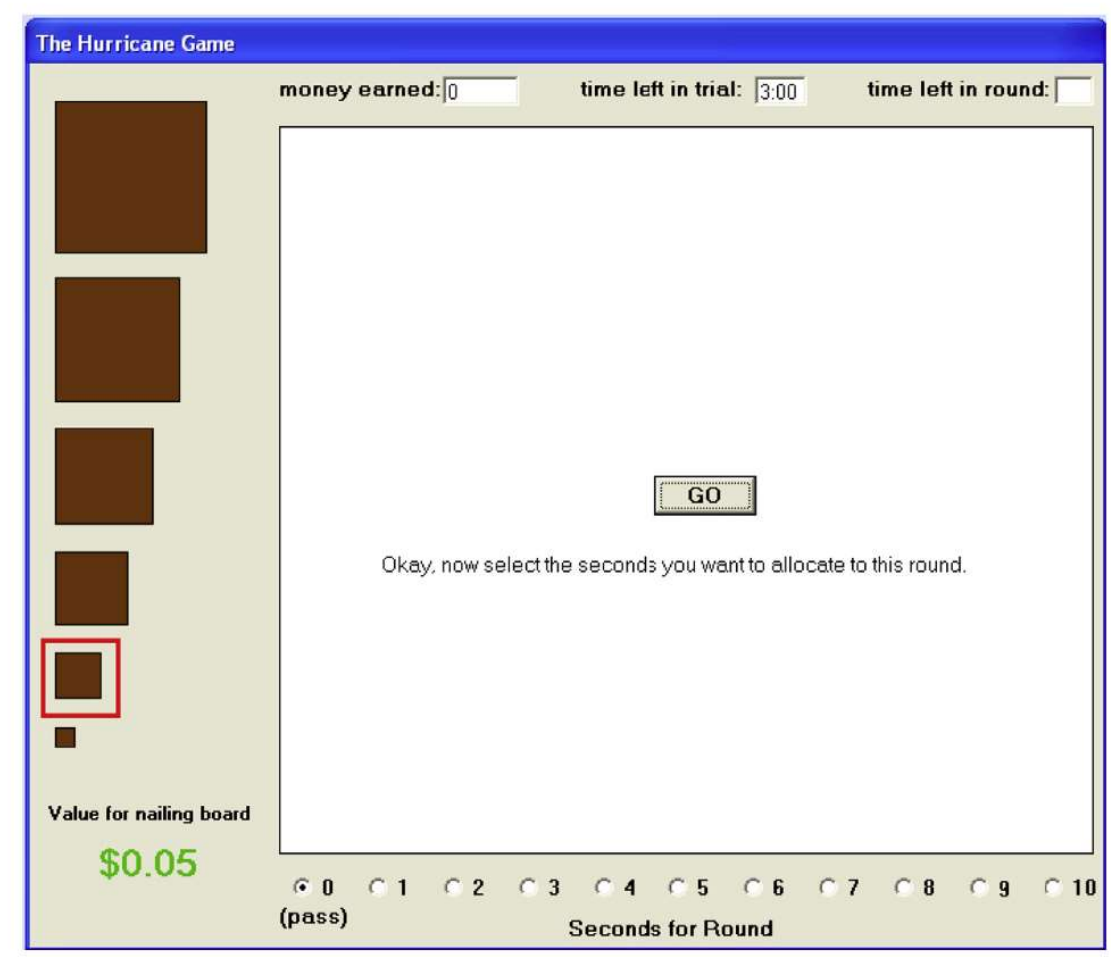

Fig. 4. "Hurricane Game" screen shot. 
There were two 3-min experimental trials, separated to provide an opportunity for the participants to rest their hands. Targets were presented one round at a time. Rounds began with the presentation of a target (i.e., the presented target is highlighted with a square, Fig. 4) as well as the value of hitting the target (i.e., indicated below the targets, Fig. 4). The round ended when the amount of time participants allocated to the round ran out. The participants could allocate anywhere between $0 \mathrm{~s}$ and $10 \mathrm{~s}$ to a round. Whatever amount was allocated was deducted from the time left in a trial. Time to make decisions regarding the presented target was not counted against the trial time limit. Nor were there any penalties for clicking the screen but missing the target. Time remaining in the round and the trial was constantly available on the computer screen. Feedback regarding the status of the target (i.e., nailed or not) was clear (i.e., target changed color and a pop-up message was displayed).

\section{Manipulations and measures}

Expectancy. Expectancy was manipulated within person via the six target sizes, as exactly used in the Vancouver et al. (2008) study. The smaller the target, the more difficult it was to hit, which affected expectancies. This later effect was confirmed by Vancouver et al. (2008), where they found a correlation of .70 between ratings of the probability of hitting the target, averaged across the various amounts of allocated time, and the size of the target. Importantly, Vancouver (2014) reported that the curvilinear relationship between the expectancy manipulation, which had been coded with integers (e.g., 0 for smallest target, 1 for second smallest, etc.), and resources allocated (i.e., degree of effort as described below) was a function of the non-linear change in target sizes across the levels of the expectancy conditions. Once corrected by coding the size of the target (i.e., its area), the relationship became linear. For this reason, we coded expectancy as the size of the target.

Value. We manipulated value within-person by providing a varying incentive for each round at two values of either \$0.05 or $\$ 0.25$ for clicking on the target, which is how value was coded in the analysis.

Resource Allocation. We used resource allocation as our measure of motivation and distinguished between direction of effort and degree of effort (Vancouver et al., 2008). Participants either passed on a round (i.e., allocated $0 \mathrm{~s}$ and clearly marked as passing; see Fig. 4) or allocated between $1 \mathrm{~s}$ and $10 \mathrm{~s}$ to try to hit the target. A dummy-coded variable was created to indicate whether participants passed (0) or not (1) for each round. This represented whether participants directed resources toward the goal of hitting the target that round and thus represented direction of effort. If the participant directed resources in the round, we used the amount of seconds allocated as our measure of degree of effort.

Performance. If the target is hit during the round, it was recoded as a 1 and otherwise 0 , which is how performance was coded in the analysis.

\section{Procedure}

Upon entering the lab, the study was described to participants. After a consenting process, participants sat at one of seven computers set in cubicles. The computer program provided all subsequent instructions, including that the objective of the task was to "nail the boards" and that the money made during the experiment was theirs to keep. Before formal experimental session, participants were led through 18 practice rounds (i.e., three 10 s rounds for each of the six target sizes) to develop expectancies for the different target sizes. Next, all participants were given a practice set where they were to allocate time to the round, but they did not receive any reward for hitting the target in the practice round. This provided an opportunity for each participant to practice the resource allocating aspect of the task

During each of the two 3-min experimental trials, targets were presented using a blocked, randomized procedure. Thus, every six rounds each target was presented, but the order was randomly determined. All participants were exposed to the same ordering of targets. Likewise, the order of the incentive values was block randomized and all participants within each experimental group were exposed to the same randomized order. Following the presentation of target, and incentive value, participants were asked to determine the number of seconds they would like to allocate to try and hit the target. If the participants allocated at least $1 \mathrm{~s}$ to the round, the round began and the target would jump (i.e. disappear and reappear at a different location within the playing area) rapidly (i.e., changing every $250 \mathrm{~ms}$ ) at randomly determined positions around the playing area until the allocated time passed or until they hit the target. If the participant hit the target, it stopped moving, changed color, and a pop-up congratulatory message was presented. Also, the amount of the value manipulation (i.e., \$0.05 or $\$ 0.25$ ) was added to their total score. However, whether or not the participants hit the target, the time allocated passed and was deducted from the total trial time.

On average, participants played 121 rounds, providing the 4051 sets of observations. Demographic information (e.g., age and gender) was collected at the end of the study and participants were paid the total amount earned across rounds. On average, participants earned $\$ 4.80(S D=2.45, \operatorname{Min}=\$ 1.3, \operatorname{Max}=\$ 10.4)$.

\section{Analyses}

Because the data was hierarchically nested, multi-level analyses were performed. Specifically, round observations (i.e., Level 1) were nested within individuals (i.e., Level 2). Analyses concerning goal choice and planning were tested using two types of multi-level statistical models. Because the dependent variable for direction (i.e., goal choice) was binary, we used a multi-level mixed effect logistic model. The conditional distribution of the dependent variable in such a model is assumed Bernoulli. For each predictor variable, we report the unstandardized regression coefficient, which is the expected change in the log odds of engagement (i.e., accepting a goal) for a unit increase in the corresponding predictor variable. To gauge model fit, we report the deviance statistic and McFadden's $R^{2}$, which Peng and So (2002) suggested is the preferred analog to $R^{2}$ in OLS regressions

We performed analyses concerning degree of effort (i.e., goal planning) using hierarchical linear modeling (HLM; Bryk \& Raudenbush, 1992). HLM allows multilevel analysis of hierarchically nested data with continuous dependent variables. Target size (expectancy) and incentive (value) were group-mean centered in all analyses (Raudenbush, 1989). Pseudo $R^{2}$ was reported for all hierarchical linear modeling analyses (Hofmann, 1997).

\section{Results}

\section{Descriptive information}

Table 2 provides descriptive information regarding the probability of hitting the target of varying sizes in the practice, as well as descriptive information regarding key outcomes of interests in the experimental session. As shown, the probability of hitting the target increases as size increased in both the practice and experimental rounds. The greater probability of hitting the target in the practice rounds can be attributed to the tendency for participants to allocate less than $10 \mathrm{~s}$ to hitting targets attempted. The probabilities for hitting the targets were comparable to the ones reported in Vancouver et al. (2008), which they found to be highly 
Table 2

Descriptive information for Study 1 in practice and experimental session.

\begin{tabular}{|c|c|c|c|c|c|c|c|}
\hline \multirow[t]{3}{*}{ Target size } & \multirow{3}{*}{$\begin{array}{l}\text { Practice session } \\
\text { Prob. of hit in } \\
\text { practice session }\end{array}$} & \multicolumn{6}{|c|}{ Experimental session } \\
\hline & & \multicolumn{3}{|c|}{ Small incentive } & \multicolumn{3}{|c|}{ Large incentive } \\
\hline & & $\begin{array}{l}\text { Perc. of } \\
\text { attempt (\%) }\end{array}$ & $\begin{array}{l}\text { Seconds } \\
\text { allocated }(S D)\end{array}$ & $\begin{array}{l}\text { Prob. of hits when } \\
\text { attempted }(S D)\end{array}$ & $\begin{array}{l}\text { Perc. of } \\
\text { attempt (\%) }\end{array}$ & $\begin{array}{l}\text { Seconds } \\
\text { allocated }(S D)\end{array}$ & $\begin{array}{l}\text { Prob. of hits when } \\
\text { attempted }(S D)\end{array}$ \\
\hline 0 (smallest) & $0.03(0.09)$ & 17.78 & $5.05(4.16)$ & $0.00(0.00)$ & 29.29 & $7.73(3.34)$ & $0.01(0.04)$ \\
\hline 1 & $0.16(0.23)$ & 29.13 & $6.48(3.56)$ & $0.11(0.18)$ & 36.18 & $7.43(2.94)$ & $0.14(0.23)$ \\
\hline 2 & $0.38(0.31)$ & 32.23 & $6.87(2.98)$ & $0.40(0.31)$ & 50.42 & $7.16(2.62)$ & $0.32(0.34)$ \\
\hline 3 & $0.59(0.27)$ & 42.61 & $6.41(2.53)$ & $0.48(0.27)$ & 67.51 & $7.35(2.27)$ & $0.52(0.24)$ \\
\hline 4 & $0.81(0.24)$ & 59.95 & $5.78(2.65)$ & $0.58(0.17)$ & 96.52 & $6.33(2.12)$ & $0.73(0.23)$ \\
\hline 5 (largest) & $0.85(0.23)$ & 63.82 & $5.32(2.78)$ & $0.77(0.23)$ & 99.39 & $5.87(2.29)$ & $0.73(0.22)$ \\
\hline
\end{tabular}

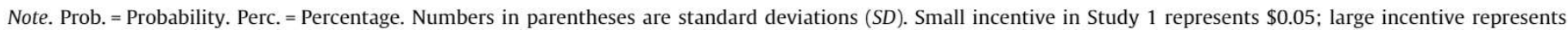
$\$ 0.25$ in Study 1. For Study 1 experiment session, $N$ of participants $=36, N$ of observations $=4051$.

related $(r=.70)$ to self-efficacy. Across the 4051 experimental trial rounds, individuals accepted the goal in 2024 rounds (49.96\%). Moreover, the probability of accepting the goal increased with target size, which was consistent with the positive expectancy effect predicted for direction (see Table 1). In general, the table shows that the smaller the target size and the larger the incentive value the more seconds allocated, which is consistent with Models b through $\mathrm{d}$ in Fig. 2 and Table 1.

\section{Effects of expectancy and value on direction of effort}

To more formally test the models of choice presented in Fig. 2 and Table 1, we performed a series of multilevel mixed effect logistic analyses (Table 3, Model 1-3). First, we tested the effect of target size (Model 1), which positively related to direction of effort $\left(\gamma=2.24, p<.01\right.$, McFaden's $\left.R^{2}=0.25\right)$. Second, we added the effect of incentive (Model 2 ), which had a positive effect on direction of effort $\left(\gamma=9.46, p<.01, \Delta R^{2}=0.17\right)$. Lastly, we added the interaction effect between target size and incentive (Model $3)$, which was positive and significant $(\gamma=9.23, p<.01$, $\left.\Delta R^{2}=0.04\right)$. The interaction is depicted in Fig. 5 . These results confirm the multiplicative function assumed in most models of goal choice and decision making (Klein et al., 2008), and were consistent with predictions from all the models in Table 1 and Fig. 2.

\section{Effects of expectancy and value on degree of effort}

To examine the role of expectancy and value during goal planning, we performed a series of multilevel mixed effects models (Table 4, Model 1-3). Recall, we described four reasonable models that differed in terms of the effects of value and the interaction of value and expectancy (see Table 1). All the models assumed expectancy was negatively related to the degree of effort. Indeed, results (Table 4, Model 1) showed that target size (i.e., manipulated expectancy) negatively related to degree of effort $(\gamma=-0.63$, $p<.01$, pseudo $R^{2}=0.13$ ). We then added the effect of incentive (Model 2), which had a positive effect on degree of effort $\left(\gamma=4.98, p<.01, \Delta R^{2}=0.11\right)$, eliminating Model a (Fig. 2; Table 1). Lastly, we added the interaction effect between target size and incentive (Table 4, Model 3), which was not significant $\left(\gamma=-1.08, p=.22, \Delta R^{2}=0.01\right)$ and thus consistent with Model $\mathrm{d}$, though the negative interaction value produced a shape approaching Model c (see Fig. 6).

\section{Performance effects}

As mentioned above, performance is a poor proxy for motivation. This is most clearly illustrated in Table 2 , which reveals that the method for manipulating expectancy (i.e., target size) also dramatically affected performance (i.e., probability of hitting target). Indeed, the means by which the manipulation presumably has its influence on expectancies is via performance feedback (Sitzmann \& Yeo, 2013; Vancouver et al., 2008). However, there are several interesting observations that can be made from the performance data described in Table 2. For instance, although participants clearly used the information about past performance and value in their goal-choice decisions, they did not use the information nearly enough to maximize their performance. Specifically, given that there was no penalty for skipping a target, participants should have only chosen the easiest target. This would maximize

Table 3

Testing effects of expectancy and incentive on direction of effort.

\begin{tabular}{|c|c|c|c|c|c|c|}
\hline & \multicolumn{3}{|l|}{ Study 1} & \multicolumn{3}{|l|}{ Study 2} \\
\hline & Model 1 & Model 2 & Model 3 & Model 4 & Model 5 & Model 6 \\
\hline \multicolumn{7}{|l|}{ Fixed effects } \\
\hline Intercept & $1.93^{* *}$ & $2.23^{* *}$ & $2.45^{* *}$ & $1.60^{* *}$ & $1.90^{* *}$ & $2.13^{* *}$ \\
\hline Target size & $2.24^{* *}$ & $3.00^{* *}$ & $3.20^{* *}$ & $2.34^{* *}$ & $3.28^{* *}$ & $3.46^{* *}$ \\
\hline Value & & $9.46^{* *}$ & $10.13^{* *}$ & & $4.87^{* *}$ & $5.56^{* *}$ \\
\hline Target size $\times$ value & & & $9.23^{* *}$ & & & $4.20^{* *}$ \\
\hline \multicolumn{7}{|l|}{ Random effects } \\
\hline Variance (target size) & $0.70^{*}$ & $0.90^{*}$ & $0.80^{*}$ & $0.78^{*}$ & $1.35^{*}$ & $0.67^{*}$ \\
\hline Variance (value) & & $88.89^{*}$ & $42.23^{*}$ & & $19.84^{*}$ & $8.36^{*}$ \\
\hline Variance (target size $\times$ value) & & & $66.20^{*}$ & & & $21.86^{*}$ \\
\hline Variance (intercept) & $7.99^{*}$ & $13.00^{*}$ & $10.77^{*}$ & $6.60^{*}$ & $12.05^{*}$ & $10.01^{*}$ \\
\hline Deviance & 3350.30 & 2776.75 & 2673.73 & 2985.75 & 1976.84 & 1917.80 \\
\hline$\Delta R^{2}$ & 0.25 & 0.17 & 0.04 & 0.27 & 0.22 & 0.03 \\
\hline$R^{2}$ & 0.25 & 0.38 & 0.40 & 0.27 & 0.43 & 0.47 \\
\hline
\end{tabular}

Note. For Study1, $N$ of participants $=36 ; N$ of observations $=4051$. For Study 2, $N$ of participants $=30 ; N$ of observations $=3121$.

$p<.05$.

** $p<.01$. 


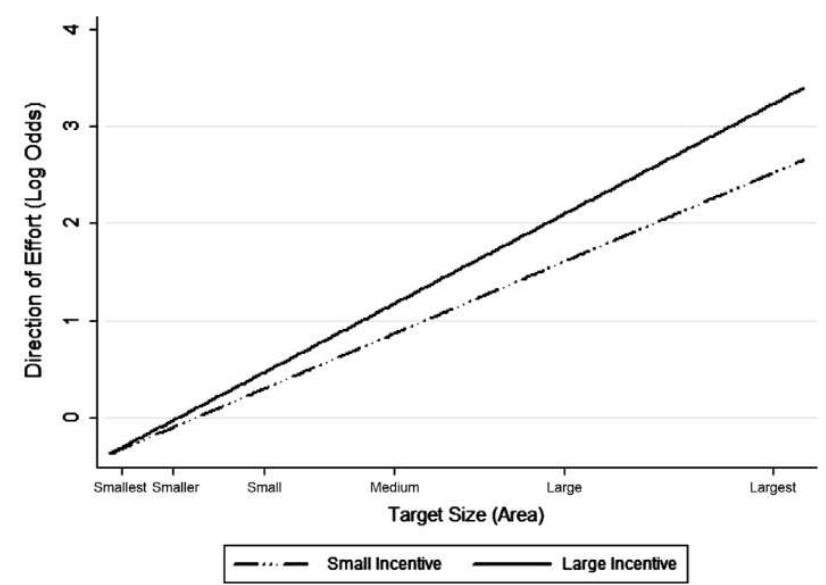

Fig. 5. Effects of incentive and target size on direction of effort (log odds) for Study 1 (based on Model 3 Table 4).

the probability of hitting the target. Also, to maximize money earned participants should have only chosen the easiest target when it was high value.

Of course, although our findings regarding the use of value suggest that participants were trying to earn money, we cannot know exactly all the various higher-level goals participants might have been considering. For some, it may have been the challenge (Atkinson, 1957). In that case, more difficult targets could represent that challenge and that motivated accepting these targets. For others, it may have been simply to maximize the number of targets hit. If this were true target value would not matter. There were a few for whom this seemed to be the case, but it was rare. Thus, it seemed many sought to earn money, but they did not know how to maximize their behavior to maximize their return.

For planning, the problem of maximizing performance was trickier. Indeed, to be worth it, another second of effort requires substantial improvements in the probability of hitting the target. For example, one's probability of hitting the target must increase by more than twice as much for it to be worth allocating two as opposed to $1 \mathrm{~s}$ (e.g., going from $5 \%$ hit rate in $1 \mathrm{~s}$ to greater than $10 \%$ hit rate in $2 \mathrm{~s})$. Yet, knowing the precise probabilities for hitting the target per second is difficult. Indeed, we did not have sufficient data for calculating each participant's optimal effort per target, though it should have always been less than the $10 \mathrm{~s}$ limit for the easiest target size and all but four participants allocated less than $10 \mathrm{~s}$ to this. Thus, it was not clear that individuals were poor goal planners, but they were far too accepting of goals in the first place.

To get a better idea of how the strategies used affected money earned, we considered correlations across the earnings of the participants and the participants' statistics for the easiest, high value targets. For example, the correlation between money earned and a person's probability of hitting the target was 0.28 , indicating talent was not a big factor by itself. The correlation between the probability of hitting the target and seconds allocated was 0.06 . Although this low correlation would appear to indicate that individuals were taking their talent into account when allocating seconds, the standard deviation in probability of hitting this target in the experimental rounds was the same as it was in the practice rounds, where seconds allocated was held at 10 (i.e., $S D=0.24$ ). Yet, the correlation between seconds allocated and money earned was -0.47 , indicating more judicious players in terms of seconds allocated (i.e., those who did not allocate a lot of time to the easy, high value targets) made more money. Indeed, this judicious behavior, coupled with how they handled the other targets, likely explains the fact that the number of these easiest, high value targets played across the $6 \mathrm{~min}$ accounted for $76 \%$ of the variance $(r=.88)$ in money earned.

Moreover, because individuals accepted and allocated resources to the different targets, we could assess the quality of their planning, independent on the quality of their decision making. That is, if one planned well, degree of effort should suppress the effect of task difficulty. Yet, target size was significantly positive $\left(\gamma=1.56, p<.1, \Delta R^{2}=0.16\right)$ when target size was used to predict performance for targets attempted (Table 5, Model 1 ). The significant, positive effect for target size on performance likely reflects difficulty (Vancouver, Gullekson, Morse, \& Warren, 2014). Indeed, when we added degree of effort to the performance model (Table 5, Model 3), effort was positively and significantly related to performance $\left(\gamma=0.26, p<.01, \Delta R^{2}=0.04\right)$, and the effect of target size increased $(\gamma=1.87, p<.01)$, implying effort was suppressing (i.e., compensating for) task difficulty to some extent, just not nearly enough to eliminate the effect of difficulty. Moreover, target value, though affecting effort, did not impact performance (Table 5, Model 2). Overall these results imply that individuals were overly conservative regarding their use of value and expectancy information when planning their resource allocation.

Finally, we wanted to consider the issue of the interaction of expectancy and value when performance was the criterion. In Model

Table 4

Testing effects of expectancy and incentive on degree of effort.

\begin{tabular}{|c|c|c|c|c|c|c|}
\hline & \multicolumn{3}{|l|}{ Study 1} & \multicolumn{3}{|l|}{ Study 2} \\
\hline & Model 1 & Model 2 & Model 3 & Model 4 & Model 5 & Model 6 \\
\hline \multicolumn{7}{|l|}{ Fixed effects } \\
\hline Intercept & $6.94^{* *}$ & $6.79^{* *}$ & $6.78^{* *}$ & $7.63^{* *}$ & $7.47^{* *}$ & $7.53^{* *}$ \\
\hline Target size & $-0.63^{* *}$ & $-0.55^{* *}$ & $-0.53^{* *}$ & $-0.84^{* *}$ & $-0.72^{* *}$ & $-0.79^{* *}$ \\
\hline Value & & $4.98^{* *}$ & $5.16^{* *}$ & & $1.98^{* *}$ & $1.60^{* *}$ \\
\hline Target size $\times$ value & & & -1.08 & & & 0.72 \\
\hline \multicolumn{7}{|l|}{ Random effects } \\
\hline Variance (target size) & $0.89^{*}$ & $0.87^{*}$ & $0.84^{*}$ & $1.08^{*}$ & $1.05^{\circ}$ & $1.07^{*}$ \\
\hline Variance (value) & & $20.67^{*}$ & $19.01^{*}$ & & $4.35^{*}$ & $3.86^{*}$ \\
\hline Variance (target size $\times$ value) & & & $11.85^{\circ}$ & & & $2.37^{*}$ \\
\hline Variance (intercept) & $2.80^{*}$ & $2.99^{*}$ & $2.98^{*}$ & $2.68^{*}$ & $2.64^{*}$ & $2.61^{*}$ \\
\hline Variance (residual) & $3.85^{*}$ & $3.44^{*}$ & $3.39^{*}$ & $3.62^{*}$ & $3.28^{*}$ & $3.22^{*}$ \\
\hline Deviance & 8674.49 & 8504.83 & 8494.64 & 6489.60 & 6380.08 & 6370.48 \\
\hline$\Delta R^{2}$ & 0.13 & 0.11 & 0.01 & 0.19 & 0.09 & 0.02 \\
\hline$R^{2}$ & 0.13 & 0.22 & 0.23 & 0.19 & 0.27 & 0.28 \\
\hline
\end{tabular}

Note. For Study $1, N$ of participants $=36 ; N$ of observations $=2024$. For Study 2, $N$ of participants $=30 ; N$ of observations $=1532$.

$p<.05$.

*. $p<.01$. 


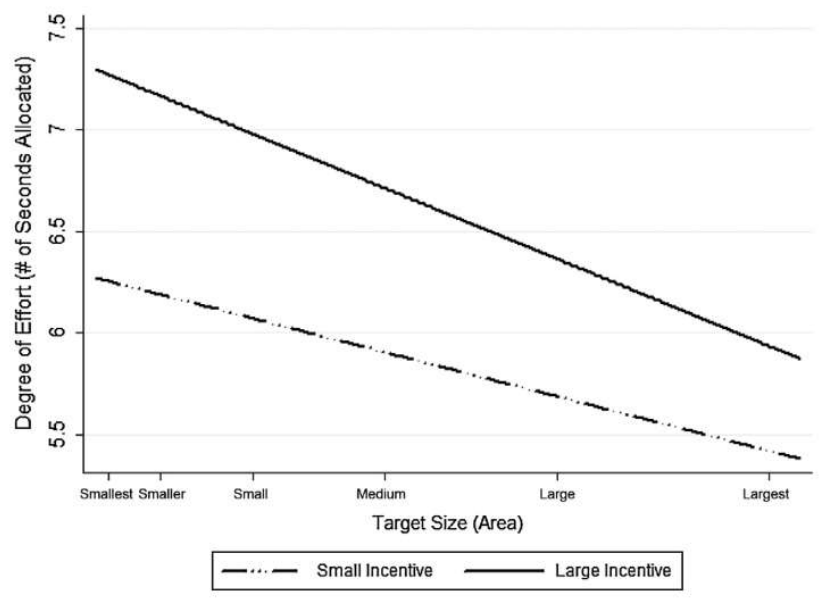

Fig. 6. Effects of incentive and target size on degree of effort in Study 1 (based on Model 3 Table 4).

4 (Table 5) we removed effort, but added the interaction term, which was not significant, but we had only included rounds where the goal was accepted. We repeated this analysis (Model 5) using all the rounds. That is, performance was coded as unsuccessful for rounds that were not attempted given that one could not hit a target not attempted. In this case, the interaction was significant $(\gamma=3.00$, $p<.05$ ). These findings further confirm that the interaction is occurring at the goal-choice stage, and, at least in this case, overwhelms the lack of an interaction occurring at the planning stage.

\section{Summary}

Synthesizing the results regarding the effects of expectancy and value on goal choice and planning, confirms the notion that the process matters. Consistent with choice models (e.g., Baron, 2004; Vancouver et al., 2010), expectancy and value positively interacted to determine choice. However, in terms of planning, we replicated Vancouver et al.'s (2008) finding that expectancy negatively affected resources allocated. We also found that value's influence was additive and positive; there was no interaction with expectancy in determining resources allocated. Overall, our results support Model d (Fig. 2, Table 1).

\section{Study 2}

The purpose of Study 2 was twofold. First, in light of recent calls for more replication (Pashler \& Wagenmakers, 2012) we wanted to provide an additional test of the effects found in Study 1. Indeed, an additional study would increase power and low power might account for the non-significant interaction found for degree of effort. Second, we sought to test the stability of the effects using a larger incentive differential. Specifically, we doubled the incentive for the higher value trials from the previous study. This also allowed us to assess whether the effect of value was qualitative or quantitative. That is, research has shown that more money does not always lead monotonically to better performance or greater effort (e.g., Camerer \& Hogarth, 1999). In the present case, we were interested in whether the greater differential between values substantially increased value's effect.

\section{Method}

\section{Participants, task, and manipulations}

Participants in this study were 30 undergraduate students who received course credit for their psychology class. These 30 participants provided 3121 sets of observations. Sixty percent of the participants were female. Their average age was 19 years old $(S D=0.96)$.

The task, procedure, and manipulations of expectancy and measures of resource allocation are exactly the same as Study 1. The only difference between Study 1 and Study 2 was that we manipulated incentive within-person by providing a varying incentive level for each round at two values of either $\$ 0.05$ or $\$ 0.50$ for clicking on the target.

On average, participants played 121 rounds, providing approximately 3121 sets of observations. Demographic information (e.g., age and gender) was collected at the end of the study and participants were paid the total amount earned across rounds. On average, participants earned $\$ 8.58(S D=5.43, \operatorname{Min}=\$ 1.85, \operatorname{Max}=\$ 27.5)$, which, consistent with the doubling of the higher incentive value, was about twice the average earned in Study 1.

\section{Results}

\section{Descriptive information}

Table 6 provides the descriptive information regarding the probability of hitting the target of varying size in the practice trials in Study 2. These probabilities are comparable to those reported in Study 1 and the study conducted by Vancouver et al. (2008). Table 6 also provides descriptive information about the average seconds allocated as a function of target value and size (i.e., expectancy). Of interest, differences in seconds allocated and proportion of high

Table 5

Testing effects of expectancy and incentive on performance.

\begin{tabular}{|c|c|c|c|c|c|}
\hline & Model 1 & Model 2 & Model 3 & Model 4 & Model 5 \\
\hline \multicolumn{6}{|l|}{ Fixed effects } \\
\hline Intercept & $-0.39^{* *}$ & $-0.40^{* *}$ & $-2.13^{* *}$ & $-0.39^{* *}$ & $-1.21^{* *}$ \\
\hline Target size & $1.56^{* *}$ & $1.57^{* *}$ & $1.87^{* *}$ & $1.56^{* *}$ & $2.20^{* *}$ \\
\hline Value & & 0.79 & -0.27 & 0.25 & $3.27^{* *}$ \\
\hline Degree of effort & & & $0.26^{* *}$ & & \\
\hline Target size $\times$ value & & & & 1.58 & $3.00^{*}$ \\
\hline \multicolumn{6}{|l|}{ Random effects } \\
\hline Variance (target size) & $0.09^{*}$ & $0.08^{*}$ & $0.11^{*}$ & $0.10^{*}$ & $0.07^{*}$ \\
\hline Variance (value) & - & 0.00 & 0.00 & 0.00 & $27.07^{*}$ \\
\hline Variance (target size $\times$ value) & - & - & - & $3.36^{*}$ & $22.62^{*}$ \\
\hline Variance (intercept) & $0.17^{*}$ & $0.16^{*}$ & $0.09^{*}$ & $0.16^{*}$ & $0.77^{*}$ \\
\hline Deviance & 2312.77 & 2310.63 & 2212.12 & 2306.22 & 2998.19 \\
\hline$\Delta R^{2}$ & 0.16 & 0.00 & 0.04 & 0.00 & 0.01 \\
\hline$R^{2}$ & 0.16 & 0.16 & 0.20 & 0.16 & 0.32 \\
\hline
\end{tabular}

Note $N$ of participants $=36 ; N$ of observations $=2024$ for Model $1-4 ; N$ of observations $=4051$ for Model 5.

$p<.05$.

** $p<.01$. 
Table 6

Descriptive information for Study 2 in practice and experimental session.

\begin{tabular}{|c|c|c|c|c|c|c|c|}
\hline \multirow[t]{3}{*}{ Target size } & \multirow{3}{*}{$\begin{array}{l}\text { Practice session } \\
\text { Prob. of hit in } \\
\text { practice session }\end{array}$} & \multicolumn{6}{|c|}{ Experimental session } \\
\hline & & \multicolumn{3}{|c|}{ Small incentive } & \multicolumn{3}{|c|}{ Large incentive } \\
\hline & & $\begin{array}{l}\text { Perc. of } \\
\text { attempt (\%) }\end{array}$ & $\begin{array}{l}\text { Seconds } \\
\text { allocated }(S D)\end{array}$ & $\begin{array}{l}\text { Prob. of hits when } \\
\text { attempted }(S D)\end{array}$ & $\begin{array}{l}\text { Perc. of } \\
\text { attempt (\%) }\end{array}$ & $\begin{array}{l}\text { Seconds } \\
\text { allocated (SD) }\end{array}$ & $\begin{array}{l}\text { Prob. of hits when } \\
\text { attempted }(S D)\end{array}$ \\
\hline 0 (smallest) & $0.03(0.10)$ & 13.43 & $6.37(4.20)$ & $0.00(0.00)$ & 29.05 & $8.47(2.87)$ & $0.05(0.19)$ \\
\hline 1 & $0.13(0.22)$ & 18.44 & $7.77(3.30)$ & $0.16(0.27)$ & 35.71 & $8.08(2.79)$ & $0.14(0.19)$ \\
\hline 2 & $0.39(0.30)$ & 29.07 & $7.82(2.57)$ & $0.32(0.34)$ & 41.27 & $7.20(2.87)$ & $0.35(0.27)$ \\
\hline 3 & $0.50(0.27)$ & 31.70 & $7.00(2.35)$ & $0.52(0.37)$ & 65.71 & $7.26(2.50)$ & $0.56(0.31)$ \\
\hline 4 & $0.78(0.27)$ & 56.81 & $5.74(2.71)$ & $0.66(0.21)$ & 99.61 & $6.67(2.33)$ & $0.69(0.28)$ \\
\hline 5 (largest) & $0.89(0.24)$ & 66.15 & $5.25(2.90)$ & $0.70(0.28)$ & 100 & $6.21(2.62)$ & $0.76(0.24)$ \\
\hline
\end{tabular}

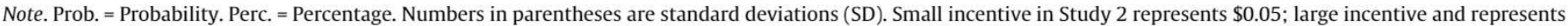
$\$ 0.50$ in Study 2. For Study 2 experimental session, $N$ of participants $=30 ; N$ of observations $=3121$.

incentive targets compared to low incentive did not differ much between studies.

\section{Effects of expectancy and incentive on direction of effort}

Table 3 (Models 4-6) shows the effects of target size and value on direction of effort. Results showed that target size (i.e., expectancy) positively related to degree of effort, $\gamma=2.34, p<.01$, $R^{2}=0.27$, value positively related to direction of effort, $\gamma=4.87$, $p<.01, \Delta R^{2}=0.22$, and the interaction term was positive and significant, $\gamma=4.20, p<.01, \Delta R^{2}=0.03$. Thus, results from these analyses replicate Study 1 and support all the models in Table 1 and Fig. 2. Of note, however, was the reduced effect for value in this study as compared to Study 1 . Specifically, the scaling of value was identical across the studies (i.e., monetary value of the target incentive), thus the smaller gamma (i.e., 9.46 versus 5.56) implies diminishing utility for higher values, which was not unexpected (Kahneman \& Tversky, 1979).

\section{Effects of expectancy and incentive on degree of effort}

Table 4 (Models 4-6) shows the effects of target size and value on degree of effort: target size (i.e., expectancy) negatively related to degree of effort, $\gamma=-0.84, p<.01$, Pseudo $R^{2}=0.19$, value positively related to degree of effort, $\gamma=1.98, p<.01, \Delta R^{2}=0.09$, and the interaction term was non-significant, $\gamma=0.72, \quad p=.10$, $\Delta R^{2}=0.02$. This result confirmed the additive model for degree of effect (i.e., Model d, Table 1 and Fig. 2). Note that in this case the non-significant interaction was positive (see Fig. 7) as compared to the negative, non-significant interaction found in Study 1, suggesting power is not the reason for the non-significant interactions.

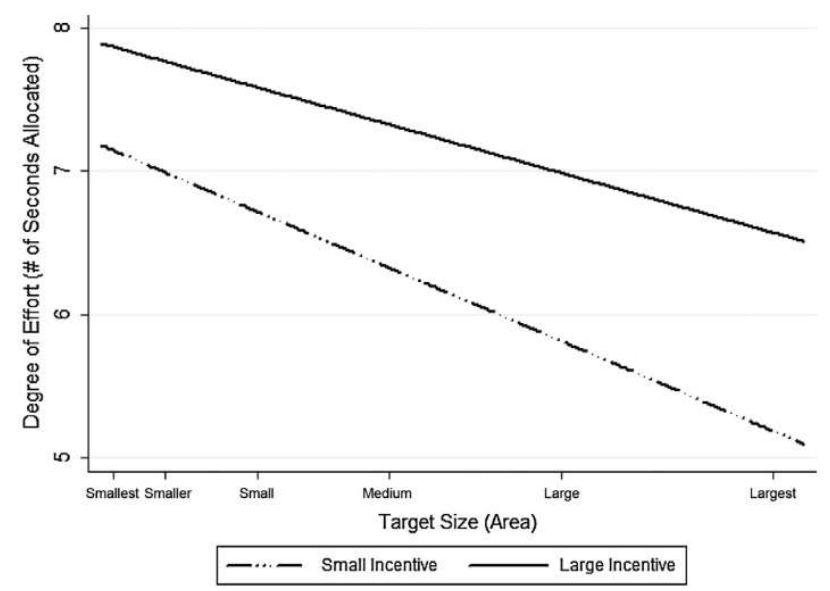

Fig. 7. Effects of incentive and target size on degree of effort in Study 2 (based on Model 6 Table 4).

\section{Performance effects}

As can be seen in Table 6, as well as the above analyses, choices and resource allocations followed similar patterns across both studies. Likewise, as in Study 1, most under-performed in terms of hits or money earned, largely due to attempting difficult and low value targets. However, in this study there was one individual who approached the optimal strategy for making money. Specifically, this individual only choose high value targets and only for the two easiest target sizes. This strategy resulted in a $\$ 27.50$ pay off, which was over $\$ 10$ more than the next highest earner, though it could have been $\$ 29$ if this individual only choose the easiest target. Perhaps because of this individual, the correlation between money made and the number of the easiest, high value targets attempted is even higher for Study $2(r=.95)$ than Study $1(r=.88)$. Ability was still only correlated 0.22 with money earned. These results suggest that ability matters, but strategy matters far more. Moreover, as found in Study 1, individuals did not sufficiently compensate for target difficulty with resources (analysis available from first author). Finally, the positive interaction between expectancy and value on performance again only appeared when all rounds were considered, as opposed to rounds attempted (analysis available from first author).

\section{Summary}

Like Study 1, the results from Study 2 regarding the effects of expectancy and value on goal choice and planning supported Model d (Fig. 2, Table 1).

\section{Discussion}

Expectancy and value have emerged as two major determinants of motivation (Kanfer, 1990; Klein et al., 2008). However, the exact nature of their functioning across goal processes is less clear (Ambrose \& Kulik, 1999; Nagengast et al., 2011; Van Eerde \& Thierry, 1996; Vancouver, 2008). Based on the recent nonmonotonic, discontinuous model of expectancy elaborated by Vancouver et al. (2008), the current study proposed that different goal processes (i.e., choice and planning) use expectancy and value in different ways, leading to different effects. To test this proposition, we conducted two studies where we measured direction of effort to assess goal-choice processes and degree of effort allocated prior to engaging to assess goal-planning processes. We also manipulated various levels of expectancy via task difficulty and value via incentives, but using a within-person design, and found that expectancy and value function differently in the goal choice versus goal planning processes. Specifically, we found that expectancy and value positively and jointly (multiplicatively) predicted one's goal choice, whereas only value retained its positive effect on the degree of effort allocated during goal planning - the expectancy effect was 
negative and the joint effect disappeared. We discuss these findings and implications below.

\section{Theoretical implications}

Findings of the different functions of expectancy and value in goal choice versus planning situation confirmed the usefulness of distinguishing goal processes in order to study precisely the role of motivational regulatory constructs (e.g., Vancouver et al., 2008). Indeed, early motivation researchers (e.g., Lewin, Dembo, Festinger, \& Sears, 1944) suggested the need to use different models to account for motivational forces in goal choice versus striving processes. However, later researchers (e.g., Atkinson, 1957) proposed that problems associated with the multiple processes could be reduced into one, and that a single model could account for motivational forces. Yet, recent research (Vancouver et al., 2008) on the usefulness of re-examination of expectancy effects in different goal processes clearly shows the need to distinguish the different goal processes.

Extending this line of research, the current study found support for the traditional $E * V$ (i.e., the multiplicative) model only for goal choice. The $E * V$ model, widely associated with Vroom (1964), but originally proposed by Lewin (1951), has been heavily researched, though often with mixed results. In general, researchers in applied settings have found little support for the multiplicative model over and above additive models (Van Eerde \& Thierry, 1996); whereas researchers in the decision making domain tend to find support for a multiplicative model (Baron, 2004; Stevenson, Busemeyer, \& Naylor, 1991). One reason for the difference might have to do with the tendency for applied researchers to inappropriately use between-person designs (Tubbs, Boehne, \& Dahl, 1993; Van Eerde \& Thierry, 1996) and another is the quality of psychological measures (Anderson, 1970); however, our research implies that another issue might be the criterion measure. That is, decision making researchers tend to measure choice, whereas applied researchers primarily use performance (Van Eerde \& Thierry, 1996). If performance is somewhat a function of choice, an interaction may be revealed. However, if individuals are in contexts where performing the task is a given, then the interaction is unlikely to emerge.

Indeed, our findings indicate that generalizing the $E * V$ model beyond goal choice may be problematic (cf. Vroom, 1964). Specifically, we found that when planning for goal achievement, not only was the multiplicative element irrelevant, but also only value was positively related to allocated resources; consistent with recent research on self-efficacy (e.g., Vancouver \& Kendall, 2006; Vancouver et al., 2008; Yeo \& Neal, 2006), expectancy had a negative effect. This finding clearly implies that goal planning and goal choice are separate processes. It also indicates that the existing mixed findings regarding additive versus the multiplicative function of expectancy and value may be partly caused by neglecting clear distinctions among different goal processes. In particular, the abstract model for expectancy and value for the goal-planning process appears to be $-E+V$.

Fortunately, the potential theoretical vacuum left by $E * V$ theory could be filled with self-regulation theories of goal striving (Lord et al., 2010). Yet, these theories lacked clarity regarding whether value has a direct effect on motivation beyond its effect on goal choices (Hyland, 1988; Locke et al., 1968; Pritchard \& Curts, 1973; Terborg, 1976;). One reason for the uncertainty is that in most research situations, scholars only statistically controlled goal levels without clearly creating goal planning situations within which levels of value are manipulated. In our study, we separated goal choice from goal planning and manipulated levels of value with incentives. Our data clearly showed that incentive played a positive role on motivation beyond its effects on goal choices.
Yet, we also found that the role of value was more qualitative than quantitative. That is, although we found that value positively related to choice and effort, the degree of the effort was essentially the same whether the high value amount was $\$ .25$ or $\$ .50$. This lack of an effect for doubling of the amount of incentive suggests that participants are using a simply heuristic to conceptualize the high value option (i.e., more than \$.05). It would be interesting to combine the incentive values in Studies 1 and 2 to confirm that $\$ .25$ and $\$ .50$ are not interchangeable amounts.

Despite the additional questions raised, the findings provide answers to some of the unresolved details needed to further develop an integrative self-regulation theory. Based on Grant and Dweck (1999) and Diefendorff and Lord (2008) articulated a taxonomy of self-regulation theories that distinguished between structural, phase, and content theories. According to this taxonomy, structural theories describe self-regulatory constructs and their generalized interrelationships. Control theory (Carver \& Scheier, 1998) and social cognitive theory (Bandura, 1997) are typical structural theories. Phase theories describe various stages of selfregulation starting from goal choice and planning. The Rubicon model of action phases is a typical phase theory (Heckhausen \& Gollwitzer, 1987; also see Vancouver \& Day, 2005). Content theories emphasize the nature and types of goals and their impact on self-regulation. Regulatory focus theory (Higgins, 1997), goal orientation theory (Dweck, 1986) and self-determination theory (Deci \& Ryan, 1985) are examples of content theories.

Diefendorff and Lord (2008) noted that each of the three approaches provides unique perspectives towards self-regulation; yet each have certain shortfalls that necessitate integration among them. For example, the structural theories focus on structural relationships between regulatory constructs without addressing what is being regulated. Phase theories elaborate various goal processes without specifying how regulatory constructs interact in each stage. In this study, we integrated the structural approach (i.e., control theory) with the phase approach, furthering effort toward an integrated theory of self-regulation. Future research needs to integrate all three approaches together by studying, for example, how constructs from content theories might moderate the relationships that we observed. This is particularly important given our finding of significant variance components in all the withinperson level effects. ${ }^{1}$ Fruitful programs are likely to emerge if researchers examine whether and how individual differences in self-regulation might moderate the within-person role of expectancy and value in affecting the direction and intensity of effort.

\section{Practical implications}

Our study has important practical implications on employee motivation. This research implies that when motivating employees, managers should first understand what motivational processes to target (i.e., setting difficult goals or encouraging proper planning) given that our research indicates that interventions might have different effects on each process. Specifically, simultaneously increasing expectancy of goal achievement and using financial incentives will greatly enhance the chances of a difficult goal will

\footnotetext{
${ }^{1}$ In our exploratory analyses, we examined the moderating roles of three individual differences variables: general self-efficacy (Chen, Gully, \& Eden, 2001), maximizing tendency (Diab, Gillespie, \& Highhouse, 2008), and need for cognition (Cacioppo \& Petty, 1982). We only found three significant moderating effects: maximizing tendency moderated expectancy's effect on degree of effort in Study 2 $(\gamma=0.78, p<.05)$, need for cognition moderated the effect of value on direction of effort in Study $1(\gamma=-10.40, p<.05)$, and the interactive effect between expectancy and value on direction of effort in Study $2(\gamma=-5.66, p<.05)$. More systematic future research are needed to explore moderating roles of other individual differences that are more pertinent to self-regulation such as regulatory focus (Higgins, 1997) and goal orientation (DeShon \& Gillespie, 2005).
} 
be accepted. However, in encouraging proper planning, it is important to help employees develop a veridical sense of their capability in reaching the goals rather than to inflate their expectancy or selfefficacy.

\section{Strengths and limitations}

The current set of studies had a number of strengths. We used a within-person design to test within-person processes (Lord et al., 2010). We manipulated variables and scaled these variables to their underlying ratio scales, which are important for testing causation (Hanges \& Wang, 2012) and the functional form of joint effects (Anderson, 1970). We included different measures of motivation (i.e., direction and degree of effort) to assess different processes (Vancouver et al., 2008). Nonetheless, our study has several limitations that future research needs to address. We discuss these below.

Although a within-person approach was used where variance was derived from the relative differences between attributions of the options, the options were presented serially (i.e., one at a time). We believe the context allowed individuals to anticipate the range of possible options coming, which allowed one to compare expected utilities (or motivational forces). However, often options are presented simultaneously and individuals can more directly compare attributes of the available choices (Baron, 2004). Because quality research using this design tends to confirm the interactional model, we do not think this is a concern. However, it may be that such a context might change the way expectancy and value are used during a subsequent planning process for accepted goals. Additional research is needed to determine if our findings generalize to this context.

The choices we made regarding the operationalization of variables may also impact generalizability. To test interactional models adequately, one should have ratio scales (Anderson, 1970). In our task, the scaling of expectancy was ratio because we used the area of the target and the scaling of value was ratio because we used the monetary value of the incentive. However, Anderson's (1970) point was that if the construct of interest is psychological, one must have some understanding of how it is scaled in the mind of the participant. Our findings clearly indicated that value was not isomorphic to the objective scale. Indeed, we largely expected this, which is why we only operationalized two levels. In terms of expectancy, we knew that the manipulated level of expectancy on resources allocated and performance changed from nonlinear ones when an ordinal scale was used (Vancouver et al., 2008) to linear ones once the manipulation was scaled to target area (Vancouver, 2014) - a finding we confirmed in the present datasets (i.e., power terms were not significant when added to the models tested). Thus, unlike the case with probability judgments (Kahneman \& Tversky, 1979) this implies that target area was isometrically transformed into expectancies. Nonetheless, we cannot be sure, thus, we can only speak directly to the objective manipulation interactions.

Indeed, generalizability could improve by examining different operationalizations of expectancy and value. That is, we used difficulty to operationalize expectancy, though Vancouver et al. (2008) also used a mastery experience manipulation and found a similar effect on the degree of resources allocated. In terms of value, we used incentives, which are both a tried and true method for manipulating value as well as a controversial one (Kohn, 1999). People may choose goals for reasons other than monetary incentives (e.g., achievement, Higgins, 1997; learning, DeShon \& Gillespie, 2005; intrinsic interests, Deci \& Ryan, 1985; or prosocial values, Grant, 2008). Research indicates that people adopt different selfregulation strategies depending on the different types of reasons (Higgins, 1997; Sun, Song, \& Lim, 2013). Future research should thus examine how these different reasons might moderate our findings to further integrate motivational theories. Indeed, as we discussed in the performance effects section, we were unsure about the superordinate goals that participants embraced in our study, which future research might address by manipulating various goals (Diefendorff \& Lord, 2008). In addition, alternative operationalizations of effort would be useful. We used time, but budget or personnel (i.e., help) might be alternative resources one might muster during a planning process to achieve a goal. Of course, our operation of goal choice was also limited. That is, we used a dichotomous (i.e., accept or not) measure; it was not about deciding what level of goal to strive for. On the other hand, because we operationalized several levels of difficulty, it seems such a generalization might not be unexpected. Moreover, a plethora of results support the notion that expectancies and value positively influence the level of goal chosen.

Another question is the generalizability of expectancy and value influences on other goal processes like goal striving and goal revision, and beyond our task contexts. Yet, some research addresses these points. For example, research by Schmidt and DeShon (2010) showed that self-efficacy negatively affects motivation and performance during goal striving when feedback about one's current state is ambiguous, consistent with the control theory reasoning of the goal planning effect (Vancouver, 2005, 2008). Goal revision processes are more complicated, depending on whether the process is engaged as a function of goal achievement, goal frustration, or multiple-goal conflict (Vancouver, 2014). In general, self-regulation theories agree that for at least the latter two processes, expectancies and value will probably match the goal-choice effects (Klein et al., 2008), but rigorous research on this question is needed.

\section{Conclusion}

Past research on expectancy and value largely dismissed the distinctions among different goal processes. The current study empirically shows that different goal processes (i.e., choice and planning) use expectancy and value in different ways, leading to different effects. These findings imply it is important to distinguish motivational processes, and that to precisely understand the roles of traditional motivational constructs, future research should elaborate how the constructs are involved with the different processes.

\section{Acknowledgment}

The work reported here was partially supported by National Science Foundation Grant SES-0851764.

\section{References}

Ambrose, M. L., \& Kulik, C. T. (1999). Old friends, new faces: Motivation research in the 1990s. Journal of Management, 25(3), 231-292.

Anderson, N. H. (1970). Functional measurement and psychophysical judgment. Psychological Review, 77(3), 153-170.

Atkinson, J. W. (1957). Motivational determinants of risk-taking behavior. Psychological Review, 64(6(1)), 359-372.

Austin, J. T., \& Vancouver, J. B. (1996). Goal constructs in psychology: Structure, process, and content. Psychological Bulletin, 120(3), 338-375.

Bandura, A. (1977). Self-efficacy: Toward a unifying theory of behavioral change. Psychological Review, 84(2), 191-215.

Bandura, A. (1986). Social foundations of thought and action. Englewood Cliffs, NJ: Prentice-Hall.

Bandura, A. (1997). Self-efficacy: The exercise of control. New York: Freeman.

Bandura, A. (2012). On the functional properties of perceived self-efficacy revisited. Journal of Management, 38(1), 9-44.

Baron, J. (2004). Normative models of judgment and decision making. In D. J. Koehler \& N. Harvey (Eds.), Blackwell handbook of judgment and decision making (pp. 19-36). London: Blackwell.

Bryk, A. S., \& Raudenbush, S. W. (1992). Hierarchical linear models: Applications and data analysis methods. Newbury Park, CA: Sage Publications. 
Cacioppo, J. T., \& Petty, R. E. (1982). The need for cognition. Journal of personality and social psychology, 42(1), 116.

Camerer, C. F., \& Hogarth, R. M. (1999). The effects of financial incentives in experiments: A review and capital-labor-production framework. Journal of Risk and Uncertainty, 19(1-3), 7-42.

Campbell, J. P., \& Pritchard, R. D. (1983). Motivation theory in industrial and organizational psychology. In M. D. Dunnette (Ed.). Handbook of industrial and organizational psychology (Vol. 2, pp. 63-130). Chicago: Rand McNally.

Carver, C. S., \& Scheier, M. F. (1982). Control theory: a useful conceptual framework for personality-social, clinical, and health psychology. Psychological Bulletin, 92(1), 111-135.

Carver, C. S., \& Scheier, M. F. (1998). On the self-regulation of behaviour. New York: Cambridge University Press.

Chen, G., Gully, S. M., \& Eden, D. (2001). Validation of a new general self-efficacy scale. Organizational Research Methods, 4(1), 62-83.

Cropanzano, R., James, K., \& Citera, M. (1993). A goal hierarchy model of personality, motivation, and leadership. Research in Organizational Behavior, 15, 267-322.

Deci, E. L., \& Ryan, R. M. (1985). Intrinsic motivation and self-determination in human behavior. Springer.

DeShon, R. P., \& Gillespie, J. Z. (2005). A motivated action theory account of goal orientation. Journal of Applied Psychology, 90(6), 1096-1127.

Diab, D. L., Gillispie, M. A., \& Highhouse, S. (2008). Are maximizers really unhappy? The measurement of maximizing tendency. Judgment and Decision Making, 3, 364-370.

Diefendorff, J. M., \& Chandler, M. M. (2011). Motivating employees. In S. Zedeck (Ed.), Handbook of industrial and organizational psychology (pp. 65-135). Washington, DC: American Psychological Association.

Diefendorff, J. M., \& Lord, R. G. (2008). Self-regulation and goal striving processes. In R. Kanfer, G. Chen, \& R. Pritchard (Eds.), Work motivation: Past, present, and future (pp. 151-196). Mahwah, NJ: Lawrence Erlbaum \& Associates.

Dweck, C. S. (1986). Motivational processes affecting learning. American Psychologist, 41(10), 1040-1048.

Edwards, W. (1954). The theory of decision making. Psychological Bulletin, 51(4), $380-417$.

Frese, M., \& Zapf, D. (1994). Action as the core of work psychology: A German approach. Handbook of Industrial and Organizational Psychology, 4, 271-340.

Gollwitzer, P. M. (1990). Action phases and mind-sets. In E. T. Higgins \& R. M. Sorrentino (Eds.). The handbook of motivation and cognition: Foundations of social behavior (Vol. 2, pp. 53-92). New York: Guilford Press.

Gollwitzer, P. M., \& Oettingen, G. (2011). Planning promotes goal striving. In K. D. Vohs \& R. F. Baumeister (Eds.), Handbook of self-regulation: Research, theory, and applications (pp. 162-185). New York: Guilford.

Grant, A. M. (2008). Does intrinsic motivation fuel the prosocial fire? Motivational synergy in predicting persistence, performance, and productivity. Journal of Applied Psychology, 93(1), 48-58.

Grant, H., \& Dweck, C. S. (1999). Content versus structure in motivation and selfregulation. In R. S. Wyer (Ed.), Perspectives on behavioral self-regulation (pp. 161-174). Mahwah, NJ: Lawrence Erlbaum Associates.

Hanges, P. J., \& Wang, M. (2012). Seeking the Holy Grail in organizational science: Establishing causality through research design. In S. W. J. Kozlowski (Ed.). The Oxford handbook of organizational psychology (Vol. 1, pp. 79-116). Oxford: Oxford University Press.

Heckhausen, H., \& Gollwitzer, P. M. (1987). Thought contents and cognitive functioning in motivational versus volitional states of mind. Motivation and Emotion, 11(2), 101-120.

Higgins, E. T. (1997). Beyond pleasure and pain. American Psychologist, 52(12), $1280-1300$

Hofmann, D. A. (1997). An overview of the logic and rationale of hierarchical linear models. Journal of Management, 23(6), 723-744.

Hyland, M. E. (1988). Motivational control theory - An integrative framework. Journal of Personality and Social Psychology, 55(4), 642-651.

Jagacinski, R. J., \& Flach, J. M. (2003). Control theory for humans: Quantitative approaches to modeling performance. Mahwah, New Jersey: Erlbaum.

Kahneman, D., \& Tversky, A. (1979). Prospect theory: An analysis of decision under risk. Econometrica: Journal of the Econometric Society, 263-291.

Kanfer, R. (1987). Task-specific motivation: An integrative approach to issues of measurement, mechanisms, processes, and determinants. Journal of Social and Clinical Psychology, 5(2), 237-264.

Kanfer, R. (1990). Motivation theory and Industrial/Organizational psychology. In M. D. Dunnette \& L. Hough (Eds.), Handbook of industrial and organizational psychology. Theory in industrial and organizational psychology (Vol. 1, pp. 75-170). Palo Alto, CA: Consulting Psychologists Press.

Kirschenbaum, D. S. (1985). Proximity and specificity of planning: A position paper. Cognitive Therapy and Research, 9(5), 489-506.

Klein, H. J. (1989). An integrated control-theory model of work motivation. Academy of Management Review, 14(2), 150-172.

Klein, H. J. (1991). Further evidence on the relationship between goal setting and expectancy theories. Organizational Behavior and Human Decision Processes, 49(2), 230-257.

Klein, H. J., Austin, J. T., \& Cooper, J. T. (2008). Goal choice and decision processes. In R. Kanfer, G. Chen, \& R. Pritchard (Eds.). Work motivation: Past, present, and future (pp. 101-150). Routledge/Taylor \& Francis Group.

Kohn, A. (1999). Punished by rewards: The trouble with gold stars, incentive plans, A's, praise, and other bribes. Mariner Books.

Lewin, K. (1951). Field theory in social science: Selected theoretical papers. Oxford, England: Harpers.
Lewin, K., Dembo, T., Festinger, L., \& Sears, P. (1944). Level of aspiration. In J. M. Hunt (Ed.), Personality and the behavior disorders (pp. 333-378). Oxford: Ronald Press.

Locke, E. A. (2004). Linking goals to monetary incentives. Academy of Management Executive, 18(4), 130-133.

Locke, E. A. (2007). The case for inductive theory building. Journal of Management, 33(6), 867-890.

Locke, E. A., Bryan, J. F., \& Kendall, L. M. (1968). Goals and intentions as mediators of the effects of monetary incentives on behavior. Journal of Applied Psychology, 52(2), 104-121.

Locke, E. A., \& Latham, G. P. (1990). A theory of goal setting E task performance. Prentice-Hall, Inc.

Locke, E. A., \& Latham, G. P. (2004). What should we do about motivation theory? Six recommendations for the twenty-first century. The Academy of Management Review, 388-403.

Lord, R. G., Diefendorff, J. M., Schmidt, A. M., \& Hall, R. J. (2010). Self-regulation at work. Annual Review of Psychology, 61, 543-568.

Lord, R. G., \& Levy, P. E. (1994). Moving from cognition to action - A control-theory perspective. Applied Psychology-an International Review-Psychologie AppliqueeRevue Internationale, 43(3), 335-398.

Miner, J. B. (2005). Organizational behavior 1: Essential theories of motivation and leadership. Armonk: M.E. Sharpe.

Mitchell, T., \& Daniels, D. (2003a). Observations and commentary on recent research in work motivation. Motivation and Work Behavior, 26-44.

Mitchell, T. R., \& Daniels, D. (2003b). Observations and commentary on recent research in work motivation. In L. Porter, G. Bigley, \& R. Steers (Eds.), Motivation and work behavior (pp. 26-44). New York: McGraw Hill.

Mitchell, T. R. (1974). Expectancy models of job satisfaction, occupational preference and effort: A theoretical, methodological, and empirical appraisal. Psychological Bulletin, 81(12), 1053-1077.

Nagengast, B., Marsh, H. W., Scalas, L. F., Xu, M. K., Hau, K. T., \& Trautwein, U. (2011) Who took the " $x$ " out of expectancy-value theory? A psychological mystery, a substantive-methodological synergy, and a cross-national generalization. Psychological Science, 22(8), 1058-1066.

Pashler, H., \& Wagenmakers, E. J. (2012). Editors' Introduction to the special section on replicability in psychological science: A crisis of confidence? Perspectives on Psychological Science, 7(6), 528-530.

Peng, C. Y. J., \& So, T. S. H. (2002). Logistic regression analysis and reporting: A primer. Understanding Statistics: Statistical Issues in Psychology, Education, and the Social Sciences, 1(1), 31-70.

Phillips, J. M., \& Gully, S. M. (1997). Role of goal orientation, ability, need for achievement, and locus of control in the self-efficacy and goal-setting process. Journal of Applied Psychology, 82(5), 792-802.

Pinder, C. C. (2008). Work motivation in organizational behavior. Psychology Press.

Powers, W. T. (1973). Behavior: The control of perception. New York, NY: Hawthorne.

Pritchard, R. D., \& Curts, M. I. (1973). The influence of goal setting and financial incentives on task performance. Organizational Behavior and Human Performance, 10(2), 175-183.

Raudenbush, S. W. (1989). Centering" predictors in multilevel analysis: Choices and consequences. Multilevel Modelling Newsletter, 1(2), 10-12.

Riedel, J. A., Nebeker, D. M., \& Cooper, B. L. (1988). The influence of monetary incentives on goal choice, goal commitment, and task-performance. Organizational Behavior and Human Decision Processes, 42(2), 155-180.

Schmidt, A. M., \& DeShon, R. P. (2007). What to do? The effects of discrepancies, incentives, and time on dynamic goal prioritization. Journal of Applied Psychology, 92(4), 928-941.

Schmidt, A. M., \& DeShon, R. P. (2010). The moderating effects of performance ambiguity on the relationship between self-efficacy and performance. Journal of Applied Psychology, 95(3), 572-581.

Schoemaker, P. J. H. (1982). The expected utility model - Its variants, purposes, evidence and limitations. Journal of Economic Literature, 20(2), 529-563.

Schwab, D. P., Olian-Gottlieb, J. D., \& Heneman, H. G. (1979). Between-subjects expectancy theory research: A statistical review of studies predicting effort and performance. Psychological Bulletin, 86(1), 139-147.

Seo, M.-G., \& Ilies, R. (2009). The role of self-efficacy, goal, and affect in dynamic motivational self-regulation. Organizational Behavior and Human Decision Processes, 109(2), 120-133.

Seo, M.-G., Barrett, L. F., \& Bartunek, J. M. (2004). The role of affective experience in work motivation. Academy of Management Review, 29(3), 423-439.

Sitzmann, T., \& Yeo, G. (2013). A meta-analytic investigation of the within-person self-efficacy domain: Is self-efficacy a product of past performance or a driver of future performance? Personnel Psychology, 66, 531-568.

Steel, P., \& Konig, C. J. (2006). Integrating theories of motivation. Academy of Management Review, 31(4), 889-913.

Stevenson, M. K., Busemeyer, J. R., \& Naylor, J. C. (1991). Judgment and decisionmaking theory. In M. Dunnette \& L. M. Hough (Eds.), New handbook of industrialorganizational psychology (pp. 283-374). Palo Alto, CA: Consulting Psychologist Press.

Sun, S., Song, Z., \& Lim, V. K. (2013). Dynamics of the job search process: Developing and testing a mediated moderation model. Journal of Applied Psychology, 98(5), 771-784.

Terborg, J. R. (1976). The motivational components of goal setting. Journal of Applied Psychology, 61(5), 613-621.

Terborg, J. R., \& Miller, H. E. (1978). Motivation, behavior, and performance: A closer examination of goal setting and monetary incentives. Journal of Applied Psychology, 63(1), 29-39. 
Tubbs, M. E., Boehne, D. M., \& Dahl, J. G. (1993). Expectancy, valence, and motivational force functions in goal-setting research: An empirical test. Journal of Applied Psychology, 78(3), 361-373.

Van Eerde, W., \& Thierry, H. (1996). Vroom's expectancy models and work-related criteria: A meta-analysis. Journal of Applied Psychology, 81(5), 575-586.

Vancouver, J. B. (2005). The depth of history and explanation as benefit and bane for psychological control theories. Journal of Applied Psychology, 90(1), 38-52.

Vancouver, J. B. (2008). Integrating self-regulation theories of work motivation into a dynamic process theory. Human Resource Management Review, 18(1), 1-18.

Vancouver, J. B. (2014, May). Turning self-regulation theory into a paradigm for psychology. Invited address presented at the Annual Conference of the Association for Psychological Science, San Francisco, CA.

Vancouver, J. B., \& Day, D. V. (2005). Industrial and organisation research on selfregulation: From constructs to applications. Applied Psychology, 54(2), 155-185.

Vancouver, J. B., Gullekson, N. L., Morse, B. J., \& Warren, M. A. (2014). Finding a between-person negative effect of self-efficacy on performance: Not just a within-person effect anymore. Human Performance, 27, 1-19.

Vancouver, J. B., \& Kendall, L. N. (2006). When self-efficacy negatively relates to motivation and performance in a learning context. Journal of Applied Psychology, 91(5), 1146-1153.
Vancouver, J. B., More, K. M., \& Yoder, R. J. (2008). Self-efficacy and resource allocation: Support for a nonmonotonic, discontinuous model. Journal of Applied Psychology, 93(1), 35-47.

Vancouver, J. B., Weinhardt, J. M., \& Schmidt, A. M. (2010). A formal, computational theory of multiple-goal pursuit: Integrating goal-choice and goal-striving processes. Journal of Applied Psychology, 95(6), 985-1008.

Vroom, V. H. (1964). Work and motivation. New York, NY: John Wiley and Sons.

Yancey, G. B., Humphrey, E., \& Neal, K. (1992). How perceived incentive, task confidence and arousal influence performance. Perceptual and Motor Skills, 74(1), 279-285.

Yeo, G. B., \& Neal, A. (2006). An examination of the dynamic relationship between self-efficacy and performance across levels of analysis and levels of specificity. Journal of Applied Psychology, 91(5), 1088-1101.

Wright, R. A., \& Brehm, J. W. (1989). Energization and goal attractiveness. In L. A. Pervin (Ed.), Goal concepts in personality and social psychology (pp. 169-210). Hillsdale, NJ: Lawrence Erlbaum Associates. 